\title{
El desafío de la televisión mexicana
}

\author{
Francisco Javier Martínez Garza \\ (Centro de Investigación de la Comunicación e Información \\ Tecnológico de Monterrey, Campus Monterrey)
}

Recibido: 17/12/2010

Aprobado: 2/2/2011

Resumen: El presente trabajo forma parte de un estudio más completo en el cual se analiza, desde diferentes miradas, el proceso electoral para elegir gobernador del Estado de Nuevo León. Para la realización del presente estudio se incluyó la información que proporcionaron a su audiencia cinco noticieros de televisión de Monterrey. El estudio realizado con base en el análisis de contenido se propuso examinar la manera como reaccionaron las televisoras a la normativa que regiría las campañas políticas en México, a partir de este proceso. El resultado indica que las televisoras prestaron poca atención en sus noticieros a la campaña, dejaron entrever, por una parte, una pobre cobertura, y por la otra, un marcado amplio desequilibrio de los contendientes.

Palabras clave: Procesos electorales / noticieros / cobertura televisiva / partidos políticos

\section{The challenge of Mexican television}

Summary: This work is part of a more comprehensive study which analyzes from different perspectives the electoral process to choose the Governor of Nuevo León. To conduct this study we included information provided by television news audience five Monterrey. The study based on content analysis proposes to analyze the way in which broadcasters reacted to the rules that govern this process from political campaigns in Mexico. The result indicated that it paid little attention to television news in the campaign, hinted on the one hand a poor coverage and the other a broad framework of the contestants imbalance.

Keywords: Elections / news, / television coverage / political parties 


\section{La cobertura del proceso}

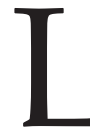

a participación que ha tenido en México la televisión durante las contiendas electorales ha sido tradicionalmente muy cuestionada, sobre todo por la inequidad con que se ha conducido. Durante los gobiernos del Partido Revolucionario Institucional (PRI) las críticas al manejo de la información fueron una constante, llegando a considerarse en aquella época que "[...] las televisoras dejaron de ejercer a cabalidad la libertad de expresión" (Acosta et al. 2009: 13).

El manejo asimétrico de la información que se proporcionó a los mexicanos por las televisoras acerca de los distintos procesos electorales ha quedado constatado a través de los monitoreos de sus contenidos informativos, realizados desde el principio de la década de 1980. El primer referente de un estudio de este tipo fue hecho por Secanella (1983), quien analizó la cobertura informativa que realizaron algunos diarios nacionales sobre los candidatos participantes en las elecciones presidenciales de 1970, 1976 y 1982. En sus conclusiones encontró un marcado desequilibrio informativo a favor del PRI (Aceves 2004).

La consolidación de este tipo de estudios se concretó con el efectuado por Arredondo y Trejo Delarbre (1991), quienes analizaron la cobertura informativa del proceso electoral de 1988 en diferentes medios de comunicación. Los resultados pusieron de nuevo en evidencia la complicidad de los medios de comunicación por favorecer los intereses del poder establecido. En el caso particular de la televisión, Arredondo estudió la información que difundieron los dos noticieros nacionales más importantes del país en aquel momento: 24 Horas (Televisa) y Día a Día (Imevisión). El autor concluyó que los dos informativos actuaron con una total displicencia en favor del candidato del PRI, de forma que el denominador que distinguió a esos noticieros "[...] radicó en su absoluta e indiscriminada entrega al candidato del partido oficial" (Arredondo 1991: 158).

Aguayo y Acosta (1997) también analizaron el comportamiento informativo que tuvieron durante la contienda de 1994 los noticieros 24 Horas (Televisa) y Hechos de la noche (TVAzteca), sus resultados evidencian que en ambos casos se favoreció en tiempo, voz, imagen y presentación a los dos candidatos a la Presidencia de la República que contendieron en este proceso electoral por el PRI, al mismo tiempo que restaron importancia a Cuauhtémoc Cárdenas (PRD) y Diego Fernández de Cevallos (PAN).

El interés por realizar este tipo de estudios se ha mantenido vigente al mismo tiempo que sus resultados se han convertido en motivo de debate político, de tal forma que muchas de las críticas relacionadas con la falta de una verdadera cultura democrática en México son atribuidas al mal desempeño de las televisoras. Una de las causas que originan la mala cobertura 
periodística televisiva, de acuerdo con Acosta (2009), es la complicidad que se ha dado entre las televisoras y el Estado, situación que les ha acarreado a estas grandes privilegios económicos y fiscales.

El poder acumulado a través de los años les ha servido para poner en práctica nuevas estrategias de negociación, ya que a diferencia de lo que sucedía aun hasta hace pocos años, cuando dependían básicamente de su relación con el Ejecutivo y el Legislativo, hoy son capaces de poner en aprietos a cualquiera, y además elegir con quién o con quiénes participar y a quién o a quiénes vetar. Su larga trayectoria en la vida pública del país les ha permitido aprender a maniobrar para elegir lo que más les conviene, de manera que cuando se percataron de que Vicente Fox tenía muchas posibilidades de alcanzar la presidencia, le brindaron un trato muy distinto al que hasta entonces habían brindado a cualquier antagonista.

La manera como se condujeron las televisoras durante el proceso electoral federal del año 2000 demostró que si bien durante mucho tiempo dependieron del apoyo de un partido político para sostenerse, el poder que lograron acumular les daba ahora la capacidad de negociación, de manera que si un gobierno o un político no les garantiza los mejores dividendos, simplemente lo relegan, como le ocurrió al entonces Secretario de Gobernación Santiago Creel, el cual no obstante haber privilegiado a Televisa con permisos para instalar casas de apuestas, lo desaparecieron del escenario político al ver que Felipe Calderón era el precandidato más fuerte del Partido Acción Nacional (PAN) para suceder a Vicente Fox.

La elección del proceso electoral federal del 2000 fue atípico en la vida política de México, ya que por vez primera en más de setenta años un partido político desligado del PRI ganó las elecciones federales, pero también lo fue porque por primera vez se ofreció en forma cuantitativa, "un trato relativamente equitativo a los candidatos y partidos" (Acosta 2009: 14).

La llegada del PAN a la Presidencia de la República presagiaba un nuevo estilo en el quehacer periodístico. Sin embargo, la contienda federal del 2006 demostró que las televisoras y el nuevo partido gobernante se adaptaron rápidamente al cambio, de manera que el manejo de la información se orientó a privilegiar al candidato del partido en el poder. Los estudios que se realizaron a los contenidos informativos refieren que durante el proceso electoral del 2006 los teleinformativos cuidaron mucho las formas, y aun cuando en lo cuantitativo presentaron una mayor equidad, en lo cualitativo se dedicaron a desacreditar al candidato que durante prácticamente toda la contienda aventajó a los representantes del PRI y del PAN en las encuestas, Andrés Manuel López Obrador, candidato de la Coalición por el Bien de Todos (Treviño y Acosta 2007). 


\section{Reformas que lesionan}

Aun cuando en las televisoras nacionales se cuidó el espacio que otorgaron a cada uno de los candidatos, en las regionales los resultados fueron distintos, ya que en estas, tanto cuantitativa como cualitativamente, la información fue tendenciosa y sesgada (Acosta 2009). Los resultados encontrados no hacen más que reforzar otra vez el presupuesto de que las televisoras actuaron como un instrumento al servicio del poder para desplazar a quien se oponga al Gobierno de la nación (Alva de la Selva 2007).

Tanto Televisa como TV Azteca tenían fuertes motivos para apoyar al candidato de Acción Nacional, ya que en el marco del proceso estaba en juego la vigencia de la Ley Televisa, la cual constituía el más importante apoyo que recibirían las televisoras nacionales de parte del gobierno foxista (20002006). La puesta en marcha de esta les habría permitido a estas instituciones mediáticas participar de los siguientes privilegios (Gómez y Sosa (2006):

a) Utilizar los "canales espejo" para sus propios fines, sin licitar y sin sufragar por ello.

b) Favorecer el otorgamiento de concesiones a los mismos concesionarios, a través de una serie de filtros o candados.

c) Evitar la participación de organizaciones sociales y restringir a las televisoras públicas la posibilidad de obtener recursos. d) Incrementar los tiempos destinados a la publicidad.

e) Gastos de campañas a cargo del Instituto Federal Electoral (IFE) y permitir la compra de propaganda y tiempo electoral a los mismos candidatos y a cualquier persona física.

Cuando todo hacía suponer que la Ley Televisa acarrearía nuevos beneficios a los conglomerados de la televisión mexicana, la Suprema Corte de Justicia de la nación decidió en contra de una buena cantidad de los artículos enumerados en la mencionada Ley, con lo cual perdieron ese privilegio. Algunos meses después, aprovechando un espacio en el cual no había ningún proceso electoral, el IFE (Instituto Federal Electoral), con el apoyo de los partidos políticos, asestaron otro golpe a las televisoras, se trató de la reducción del tiempo de las campañas y, sobre todo, se elevó a rango constitucional la prohibición para que cualquier persona física o moral adquiera tiempo para difundir propaganda durante las campañas políticas.

Las televisoras estaban conscientes de que la puesta en práctica de ambas medidas implementadas vendrían a impactar severamente en sus ganancias, por lo que reaccionaron de manera fuerte y decidida. Su argumento era que al entrar en vigor la mencionada ley se estaría violando la libertad de expresión de los mexicanos. En su defensa nunca mencionaron, ni siquiera en forma velada, que la implementa- 
ción de las nuevas reglas les afectaría mucho en sus ingresos.

La reducción del tiempo de campaña y la prohibición para la compra de tiempo en los medios electrónicos fue celebrada por un buen sector de la sociedad mexicana, los cuales desde mucho antes habían cuestionado el alto costo que las campañas representaban para el pueblo mexicano. De acuerdo con las cifras del IFE, durante el proceso electoral federal del 2006, solo el PAN reportó un costo de 221,4 millones de pesos, de los cuales el 98,9 por ciento se destinó al pago de la campaña en televisión y la radio. Alianza por México gastó 367,7 millones, 94,3 por ciento de los cuales se canalizaron a los mismos medios, y la Coalición Por el Bien de Todos liquidó 359,1 millones de pesos, de los cuales el 99,6 por ciento se aplicó a la radio y la televisión. El Partido Nueva Alianza (Panal) gastó 23,1 millones de pesos (95,7 por ciento) en medios electrónicos y el Partido Alternativa Socialdemócrata y Campesina (PASC) tuvo una cuenta de 6,6 millones de pesos, de los cuales el 100 por ciento fue invertido en la adquisición de espacios en los mismos medios (Herrera 2006). En términos generales, las cifras que reporta el IFE en relación con esta contienda reflejan que solo en esa campaña las televisoras obtuvieron una ganancia cercana a los 1.000 millones de pesos.

No obstante la presión de la que fueron objeto un grupo de legisladores por parte de las televisoras, estos se mantuvieron firmes y las reformas se aprobaron. La reacción de las televisoras no se hizo esperar y a través de sus contenidos informativos trataron de confundir a la sociedad. Como ejemplo de lo anterior se destaca la suspensión de los juegos de futbol a mitad del partido, justificándose en un cintillo en cuya leyenda se argumentaba que se tomaba la decisión para dar cumplimiento a las disposiciones del IFE.

La manera en la que procedieron las televisoras se interpretó como un desacato a las autoridades mexicanas, provocando una fuerte pugna entre la clase política y las televisoras. Sin embargo, aprovechando la situación y el malestar de este medio no faltó algún dirigente partidista que tratara de enmendar la situación buscando congraciarse con ellas. Entre ellos destaca quien fuera el coordinador de la fracción priista en el Senado, Manlio Fabio Beltrones, el cual abogó por que se eliminaran las sanciones a las televisoras. Mientras que el PAN quitó de la coordinación de su partido en el Senado a Santiago Creel, que para entonces se había convertido en uno de los principales críticos del poder mediático.

Otros miembros del PRI -sobre todo gobernadores- también incurrieron en la compra de espacio y tiempo en programas de las televisoras; la derrama de dinero del erario público ha sido desde entonces devastador. El gobernador del Estado de México Enrique Peña Nieto ha sido el más re- 
currente, al grado de convertirse en el personaje más popular de los informativos y programas de entrevistas en la televisión mexicana. Un monitoreo realizado por el Senado de la República encontró que en los 44 días posteriores a la aprobación de la reforma electoral, la información sobre el Congreso y sus legisladores cayó de manera dramática, mientras que Peña Nieto

[...] registra más de 700 menciones en ese periodo, en una sobreexposición también anómala, Congreso y legisladores literalmente desaparecen de las pantallas en una clara represalia informativa (Aristegui 2008).

\section{La visión académica}

La atención que han prestado a los contenidos de la televisión los académicos y los miembros de la sociedad civil obedece a la presuposición que existe en cuanto que este medio se ha llegado a convertir en el principal referente de los mexicanos sobre lo que ocurre en la vida política. Esa es también una de las principales razones por la que los políticos procuran no enemistarse con dicho medio, sabedores de que juega el papel de intermediario con sus votantes, por lo que la relación que establezcan con este será determinante para su carrera.

McLeod y su equipo de trabajo sostienen que la participación de los medios en la política electoral impacta en las personas de diferente manera. Por una parte, intervienen en la conformación de la opinión pública y en algunos casos también inciden en la decisión de los votantes, aun cuando los trabajos realizados tiempo atrás por Lazarsfeld no lo reconocen. De acuerdo con McLeod, algunos estudios más recientes han encontrado evidencias de que sí participan en la conformación de actitudes y en el reforzamiento de normas sociales (1996: 185). El mismo equipo refiere también que existe evidencia de que la exposición que tienen las personas ante los medios impacta en sus cogniciones tal y como lo proponen las teorías de la Agenda, la del efecto priming, la de adquisición de conocimientos y la del encuadre.

La Agenda Setting es una de las propuestas teóricas referidas al impacto que los contenidos de la televisión tienen en la cognición de las personas. El presupuesto de dicha teoría es que la relevancia que los medios confieren a un determinado tipo de información se transfiere al cerebro de las personas (McCombs 2006). Así, es posible suponer que los contenidos destacados durante la contienda electoral en los noticieros de la televisión adquieran importancia en la vida del público. Por ello, es importante para algunos académicos como McCombs conocer de qué manera los medios configuran los temas del día.

La configuración de la información que se transmite al público ha sido abordada en el "segundo nivel" de la 
teoría de la Agenda. El concepto fue desarrollado a finales de la década de 1980 por Iyengar y Kinder (1987) y se le conoce como "efecto priming". Este efecto consiste en analizar la forma como los medios presentan la información que se difundirá, ya que a partir de ahí será posible deducir la primera lectura que le dará el público a la temática presentada. En ese sentido, para el análisis de esta segunda propuesta se repara en la colocación de la nota, en su dimensión y en la frecuencia con la que aparece, entre otras cosas.

También desde la sociología de la producción de mensajes (newsmaking) se ha reparado en la manera en que las instituciones de medios conforman y configuran las noticias. Shoemaker y Reese (1991) sostienen que existe una serie de condicionantes que impactan el contenido que se ofrece a través de los medios de comunicación; tal es el caso de las políticas editoriales, las características individuales de los reporteros, las características de la organización, la relación que se tenga con fuerzas externas como los anunciantes o el control gubernamental. Sin embargo, en prácticamente la mayoría de los casos el factor determinante en el tipo de contenidos que se presentan en el medio tiene que ver con los aspectos financieros, ya que muchas de las empresas de prensa tienen que rendir cuentas a sus accionistas, de ahí que se orienten por la búsqueda de mayores ganancias. Autores relacionados con el campo del periodismo como Gans (1979) o Sigal (1973) han reparado en lo anterior; por ello, consideran el aspecto económico como una limitante del trabajo informativo.

\section{La propuesta}

Las posturas académicas referidas permiten presuponer que la información que se presente al público de este país habrá de participar de manera importante en su decisión de voto, pero también habrá de incidir mucho en el modo en que se habrá de construir un Estado más o menos fuerte. La forma como se han conducido los noticieros de la televisión no han hecho más que reflejar en sus contenidos las políticas editoriales que les reditúan mayor beneficio.

Los reveses y las adversidades sufridos por la televisión mexicana durante los últimos años han sido atípicos, ya que con excepción de contadas situaciones, durante la mayor parte de su existencia este medio ha sido sumamente protegido, convirtiéndose, gracias a ello, en una de las industrias más rentables del país hasta pasar a ser una de las instituciones más poderosas e influyentes de México.

Con base en los antecedentes referidos es posible presuponer también que las televisoras no están dispuestas a dar un paso atrás ante lo que estas pudieran considerar como una pérdida para sus intereses. Se saben pode- 
rosas y están conscientes de la fuerza que han tomado durante los últimos diez años, es por ello que en el presente trabajo nos proponemos identificar la cobertura informativa que se presentó en la televisión de la ciudad de Monterrey sobre el proceso electoral para elegir gobernador del Estado de Nuevo León en el 2009.

La importancia de este estudio radica en que es justo en este proceso donde se pondrán en práctica por vez primera las reformas electorales realizadas a la ley del Código Federal de Instituciones y Procedimientos Electorales (Cofipe). Representa también la oportunidad de conocer la manera como se habrán de conducir los grupos políticos, habida cuenta de que las elecciones intermedias han sido consideradas desde hace algunos años en México como una especie de termómetro de lo que se avecina para las elecciones federales, ya que a través de ellas es posible atestiguar sobre la capacidad y la movilidad de cada uno de los partidos políticos y de los diversos actores.

Para responder al planteamiento del estudio, nos propusimos responder las siguientes preguntas de la investigación:

a) ¿Cuál fue la cobertura ofrecida por los noticieros de televisión de Monterrey sobre el proceso electoral para elegir gobernador del Estado en el 2009?

b) ¿En qué medida las televisoras difundieron la información relacio- nada con la plataforma electoral de los contendientes?

c) ¿Qué tan equitativa fue la cobertura informativa que se hizo de los distintos candidatos a la gubernatura del Estado de Nuevo León?

d) ¿Cuál fue el tratamiento periodístico que se ofreció sobre cada uno de los candidatos en los informativos analizados?

\section{El método}

Para realizar el estudio se recurrió a la técnica de análisis de contenido cuantitativo, enfocando la atención en una muestra que comprende seis noticieros de la televisión regiomontana: Tele Diario (Canal 12), matutino y nocturno, del grupo Multimedios Estrellas de Oro; Las Noticias Monterrey (Canal 34), matutino y nocturno de Televisa Monterrey; Info 7 (Canal 7), matutino, forma parte de TV Azteca Noreste.

La muestra, realizada conforme a un censo, se integró con la información que se transmitió de lunes a viernes, de 6 a 10 de la mañana y de 7 a 9 de la noche, y abarcó desde la primera semana de abril hasta la primera semana de julio. En la muestra de la información se incluyen solo noticias, reportajes, crónicas, ruedas de prensa, entrevistas exclusivas generadas dentro y fuera de las instalaciones de las televisoras, y se excluyó la propaganda.

La fiabilidad de levantamiento de la información se midió sobre la base del 
método Holsi (Wimmer y Dominick 1994), el cual considera que el "acuerdo mínimo" para calificar los datos como fiables es de 0.80. Esto significa que en este tipo de trabajos existe un margen de error permitido de hasta 20 por ciento (Igartua 2006: 221).

$$
\text { Fiabilidad }=\frac{2 M}{N_{1}+N_{2}}
$$

Los rangos de fiabilidad alcanzados en el trabajo realizado por parte de los codificadores muestran que, en lo que se refiere al tono de la noticia, se alcanzó un PA $=.86$. En lo que corresponde al tratamiento periodístico que se efectuó sobre los candidatos mostró resultados aceptables: $\mathrm{PA}=.83$ (17\% error) y PA.= .84 (16\% de error), respectivamente. Por lo tanto, se reconoce que la base de información en la que se sustenta el estudio cuenta con la fiabilidad requerida.

La unidad de análisis fue la nota periodística y el personaje, que en esta ocasión estuvo conformada por los candidatos participantes a la gubernatura: Ernesto Villarreal Landeros (Partido Social Demócrata/PSD); Fernando Elizondo Barragán (PAN); Guillermo Beltrán Pérez (Panal); Martha Ofelia Zamarripa Rivas (PRD) y Rodrigo Medina de la Cruz (Juntos por Nuevo León, PRI, Partido Verde Ecologista de México/PVEM, y las agrupaciones locales Partido Demócrata y Cruzada Ciudadana).

Además, se consideró como unidad de análisis el tiempo o duración de la noticia y la ubicación de esta. A partir de la información señalada, fue posible realizar una serie de cruces de información.

\section{Los resultados}

Actualmente, en la mayor parte de las sociedades del mundo contemporáneo el espacio público pasa y se da a conocer a través de los medios de comunicación masiva (Aceves 2004: 92). La mayor parte de los ciudadanos del país llegan a conocer o a desconocer los acontecimientos relacionados con las campañas políticas gracias a estos, de ahí la importancia de conocer la manera como trabajaron la información. Es evidente, de acuerdo con los resultados de estudios realizados durante otras contiendas, que el solo hecho de que se transmita la información a través de estas instituciones no garantiza la calidad del tratamiento ni el enfoque periodístico que se les brinde. Esta situación adquiere una gran relevancia, sobre todo si se considera que tanto lo que se diga como lo que se deje de decir, o la manera en que se presenten los hechos, son situaciones que finalmente se reflejarán en el tipo de conocimiento que las personas tendrán de los procesos electorales.

\section{La cobertura}

Los noticieros de la ciudad de Monterrey transmitieron 243 notas vinculadas al proceso electoral para elegir 
gobernador del Estado de Nuevo León en el 2009. En relación con dichas informaciones se transmitieron 7 horas y 18 minutos, cantidad que representa el 1 por ciento de las 720 horas de información total que transmitieron los noticieros de televisión incluidos en la muestra durante los tres meses que duró la campaña electoral.

En promedio, el tiempo que diariamente destinaron las televisoras a transmitir la información relacionada con el acontecimiento electoral fue de alrededor de 1 minuto y 20 segundos. Es decir, muy poco tiempo, sobre todo si se compara con el que dedicaron los informativos de dos Estados de la República en su oportunidad al mismo tema. Para el caso, los noticieros de televisión de Yucatán le dedicaron a un proceso electoral similar al de Nuevo León diariamente en promedio $3 \mathrm{mi}-$ nutos y 50 segundos, mientras que en el Estado de Baja California, fue de 4 minutos y 10 segundos (Acosta 2009).

La diferencia en el tiempo que destinaron los informativos de otros Estados del país a la contienda electoral para elegir a su gobernador también se hace evidente entre las televisoras de Monterrey, ya que entre estas existen notables disimilitudes en el tiempo que destinaron a la cobertura del tema. La disparidad es tal, que por sí mismo el noticiero matutino de Televisa Monterrey fue el que más de la mitad del tiempo (51\%) dedicó al tema en relación con la totalidad de los informativos (tabla 1). Este mismo noticiero fue, a la vez, el que difundió la mayor cantidad de notas $(41,6 \%)$. En promedio, el mencionado informativo destinó 3 minutos y 50 segundos.

El matutino Info 7, perteneciente a la cadena TV Azteca, fue el segundo en destinar diariamente en promedio

Tabla 1

Espacio que dedicaron los noticieros al proceso electoral

\begin{tabular}{lcc}
\hline Noticieros televisivos & $\begin{array}{c}\text { Notas } \\
\%\end{array}$ & $\begin{array}{c}\text { Tiempo (seg) } \\
\%\end{array}$ \\
\hline Las Noticias & 41,6 & 51,7 \\
Info 7 & 27,2 & 18,8 \\
Telediario (mañana) & 13,6 & 9,6 \\
Las Noticias Mty (noche) & 11,1 & 11,9 \\
Telediario (noche) & 6,6 & 7,9 \\
Total & 100,0 & 100,0 \\
& $(\mathrm{n}=243)$ & $(\mathrm{n}=24,429)$ \\
\hline
\end{tabular}


una mayor cobertura sobre el evento (1 minuto y 10 segundos). El resto de los noticieros no llegaron a transmitir sobre el tema, ni siquiera un minuto en promedio diariamente. El poco tiempo destinado por las televisoras a la transmisión del evento político denota el poco interés que tuvieron las empresas televisoras por difundir la información relacionada con el acontecimiento político.

De acuerdo con algunos autores, por ejemplo McCombs (1996), los medios de comunicación otorgan a la noticia mayor o menor importancia, y que esta situación es interpretada por el público de los medios, pues este ha aprendido a identificar ese tipo de detalles. Durante la contienda electoral celebrada en el 2009 en Nuevo León, los noticieros de la televisión presentaron la mayoría de los contenidos (86\%) del cuarto segmento en adelante. Específicamente, en horario matutino la mayor parte de la información (85\%) de este tipo se dio a conocer entre las 8.30 y las 9.00 de la mañana, esto significa que la información relacionada con el proceso electoral se presentaba cuando la mayoría de las personas en posibilidades de votar ya se habían retirado o se aprestaban a incorporarse a sus labores cotidianas. Una situación similar se encuentra también entre los noticieros nocturnos.

\section{Los temas}

La información periodística la constituyen los contenidos que se trans- miten al público; en ese sentido, debe repararse en la manera como se va elaborando el producto antes de ser transmitido. De acuerdo con Shoemaker y Reese (1994), existe una serie de condicionantes que toman parte en la construcción de las noticias, y entre estos destacan desde factores relacionados con los propios periodistas (condicionantes individuales) hasta aquellos que dependen de las políticas de la organización.

La información que se transmitió a través de los noticieros de la televisión regiomontana no estuvo exenta de este tipo de situaciones, en principio porque fueron los propios periodistas quienes finalmente decidían qué se publicaría y qué no se daría a conocer. Además, son también los periodistas los que deciden el tratamiento periodístico que se habrá de otorgar a la información; por lo tanto, el grado de profundidad o de superficialidad con que se presente un determinado tema depende de ellos. Es común que la cobertura electoral se realice con base en la idea de que la política es un juego estratégico en el cual los actores están compitiendo y se dejan a un lado los aspectos que brindan un mayor nivel de profundidad; por lo que es poco el tiempo que se destina para discutir temas públicos y analizar las causas, soluciones, alternativas para resolverlos (Berganza 2008).

Los temas difundidos en los noticieros de televisión que han sido analizados durante el marco de la contienda 
electoral se basaron principalmente en aspectos que poco o nada orientaban al público a tomar una decisión para elegir al candidato por quien habrían de emitir su voto. Se trató sobre todo de noticias matizadas de sensacionalismo en las cuales se destacaban las declaraciones generadas por los grupos de seguidores, especialmente las que partían de los candidatos más fuertes en la contienda (16 por ciento). En segunda instancia se destacaba la información vinculada a la inseguridad pública, en donde principalmente se refería a ella, pero sin elaborar propuestas (15 por ciento). Se trató también de las agresiones que se suscitaron entre los candidatos (11 por ciento). Otro de los temas a los cuales se le prestó importancia tuvo que ver con la salud, pero ello se debió más que nada a los problemas derivados del virus del AH1N1.

La guerra de las encuestas (4 por ciento), las críticas a la corrupción (4 por ciento) y la confrontación de las campañas en internet (4 por ciento) fueron otros de los temas favoritos de las televisoras. Poco se habló en los informativos sobre la crisis económica que tanto agobia a la región y al país, o de los planes orientados al mejoramiento de los servicios públicos y los dedicados a la educación y a la atención de las personas de la tercera edad.

Por lo general, cuando en los informativos se hacía referencia a la contienda electoral se aludía a los temas vinculados a la inseguridad, pero sin reparar en soluciones y se destacaban los resultados de las encuestas y los debates, pero sin hacer un análisis de estos, solo se dedicaban a decir quién va ganando y quién va a ganar de acuerdo a la tendencia. El análisis realizado a las notas que se transmitieron refiere que en la mayoría de los casos las televisoras se concretaron a transmitir información muy superficial del acontecimiento (97 por ciento), mostrando de esa manera poco compromiso con su público.

\section{La equidad informativa}

Toda empresa periodística debería tener en cuenta entre sus objetivos el de informar de la mejor manera posible a su público. En el caso de los procesos electorales, se podría esperar que los medios actuaran al menos con equidad, informando por igual de cada uno de los participantes. A diferencia de lo que sucede con otro tipo de acontecimientos, en las campañas políticas es posible planear previamente la realización de una buena cobertura, ya sea las giras, las entrevistas, los mítines, etcétera.

Este tipo de acontecimientos favorecen la labor periodística, al permitir a los reporteros recoger mayor cantidad de información, así como un contacto más directo con los principales actores políticos. De acuerdo con la denominación de Sigal (1993), la cobertura de las campañas electora- 
les podría ser considerada como una fuente rutinaria. Sin embargo, desde la redacción de los medios se envía a los redactores a los lugares que según los editores son los más noticiables o que mejor convienen a los intereses de las empresas periodísticas.

En ese sentido, es en la sala de redacción o en la dirección del medio donde se planean y filtran los acontecimientos a los cuales se les brindará cobertura. Ahí se cuenta con la agenda de cada uno de los candidatos, ya que la mayoría de las veces esta es enviada con anticipación por el jefe de prensa de la campaña, situación que facilita su cobertura periodística. Con base en la agenda que se les hizo llegar, los noticieros de televisión se nutrieron de una buena parte de la información que posteriormente transmitieron a su público.

Sin embargo, los resultados indican que en los noticieros de la ciudad de Monterrey existió una severa inequidad, ya que estos enfocaron la atención principalmente en solo dos de los cinco candidatos. Se trata de los candidatos del PRI y del PAN, Rodrigo Medina y Fernando Elizondo, respectivamente. El resto de los candidatos recibió muy poca atención por parte de los medios, o en el peor de los casos pasaron inadvertidos.

De las 229 notas periodísticas en las que los noticieros analizados ofrecieron información exclusivamente sobre un solo candidato, la mayoría de ellas (91\%) enfocaron su atención exclusivamente en los candidatos del PRI o el del PAN. En ese sentido, los informativos ofrecieron una visión muy sesgada de la contienda. La diferencia a la que se alude es similar si se considera el número de notas y el tiempo que las televisoras destinaron a cada uno de los candidatos (tabla 2).

Las entrevistas exclusivas realizadas a los candidatos en los noticieros de la televisión fueron uno de los re-

Tabla 2

Espacio que se le concedió a cada uno de los candidatos en la contienda

\begin{tabular}{lrrrr}
\hline Candidato & Notas & $\begin{array}{c}\text { Notas } \\
\%\end{array}$ & $\begin{array}{c}\text { Tiempo } \\
(\mathrm{seg})\end{array}$ & $\begin{array}{c}\text { Tiempo } \\
\%\end{array}$ \\
\hline Rodrigo Medina & 106 & 46,3 & 10.788 & 46,0 \\
Fernando Elizondo & 103 & 45,0 & 11.470 & 49,0 \\
Martha Zamarripa & 7 & 3,1 & 795 & 3,4 \\
Guillermo Beltrán & 9 & 3,9 & 228 & 1,0 \\
Ernesto Villarreal & 4 & 1,7 & 147 & 0,6 \\
Total & 229 & 100,0 & 23.428 & 100,0 \\
\hline
\end{tabular}


cursos periodísticos más utilizados durante la contienda. En total se realizaron 41 entrevistas en los foros de los mismos noticieros, de estas una tercera parte se efectuó en el noticiero matutino de Televisa Monterrey (14). El noticiero nocturno de esta misma empresa fue el que presentó, en segunda instancia, la mayor cantidad de entrevistas exclusivas en el estudio (9). Del total de entrevistas que realizó durante la campaña este último canal de televisión, en 13 participa el candidato del PRI y en nueve el del PAN.

Las entrevistas exclusivas constituían una magnífica oportunidad para que los candidatos tuvieran la oportunidad de presentar a la ciudadanía su oferta de trabajo y los programas de acción que habrían de emprender de llegar a ocupar la gubernatura. Sobre todo contaban con un margen mayor de tiempo, de manera que representaba también una valiosa oportunidad para que los votantes pudieran identificar en los candidatos una serie de aspectos cualitativos que de otra manera no podría reconocer en ellos: liderazgo, seguridad, sentido del humor, etcétera. El sesgo en el manejo de la información fue tal que en solo una de las 41 entrevistas se incluyó a un candidato diferente al de los partidos mencionados.

\section{Tratamiento de la información}

Para las televisoras de la ciudad de Monterrey, solo fueron dos los candidatos que disputaron la gubernatura del Estado de Nuevo León, ya que el resto de los candidatos pasó desapercibido para estas. Como se expuso en el apartado anterior, estas empresas de televisión se dedicaron a difundir información relacionada con los candidatos de los dos partidos políticos más fuertes de la región, en lo que concierne al número de votos y a recursos económicos. Sin embargo, de acuerdo con los autores existen algunos aspectos que también inciden en la percepción del público, y en ello juega un papel destacado la manera como se da a conocer o se presenta la información. (tabla 3)

El análisis realizado refiere que Fernando Elizondo, candidato del PAN, fue de quien se transmitió la mayor cantidad de notas en los noticieros de televisión, esto es, casi 10 notas más que sobre Rodrigo Medina, candidato del PRI. Sin embargo, desde el punto de vista cualitativo, a Elizondo se le vinculó en mayor proporción con aspectos y situaciones negativas. De esa forma, es posible presuponer que su imagen haya impactado negativamente en la percepción del público de este medio. En términos generales, todas las televisoras contempladas en el estudio ofrecieron la mayor cantidad de noticias negativas sobre Elizondo.

En la tabla 3 no se hace referencia a la evaluación del resto de los candidatos de los partidos contendientes ya que además de que estos aparecieron en contadas ocasiones, en ningún caso se proporcionó información negativa 
Tabla 3

Clasificación de los contenidos que se difundieron sobre los candidatos

\begin{tabular}{lccccc}
\hline $\begin{array}{l}\text { Televisa Monterrey } \\
\text { Matutino }\end{array}$ & $\begin{array}{c}\text { Núm. de } \\
\text { notas }\end{array}$ & $\begin{array}{c}\text { Tiempo } \\
(\mathbf{m i n})\end{array}$ & $\begin{array}{c}\text { Favor } \\
\%\end{array}$ & $\begin{array}{c}\text { Neutral } \\
\%\end{array}$ & $\begin{array}{c}\text { Contra } \\
\%\end{array}$ \\
\hline Rodrigo Medina & 40 & 45,2 & 36.7 & 62.3 & 1 \\
Fernando Elizondo & 44 & 48,1 & 40.1 & 40.2 & 19.8 \\
Total & 94 & 203 & & & \\
\hline
\end{tabular}

\begin{tabular}{lccccc}
\hline $\begin{array}{l}\text { Televisa Monterrey } \\
\text { Nocturno }\end{array}$ & $\begin{array}{c}\text { Núm. de } \\
\text { notas }\end{array}$ & $\begin{array}{c}\text { Tiempo } \\
(\mathbf{m i n})\end{array}$ & $\begin{array}{c}\text { Favor } \\
\%\end{array}$ & $\begin{array}{c}\text { Neutral } \\
\%\end{array}$ & $\begin{array}{c}\text { Contra } \\
\%\end{array}$ \\
\hline Rodrigo Medina & 14 & 54,9 & 95,3 & 4.7 & \\
Fernando Elizondo & 12 & 45,1 & 60,7 & 29 & 10,3 \\
Total & 26 & 48 & & & \\
\hline
\end{tabular}

\begin{tabular}{lccccc}
\hline $\begin{array}{l}\text { TV Azteca / Info 7 } \\
\text { Matutino }\end{array}$ & $\begin{array}{c}\text { Núm. de } \\
\text { notas }\end{array}$ & $\begin{array}{c}\text { Tiempo } \\
(\mathbf{m i n})\end{array}$ & $\begin{array}{c}\text { Favor } \\
\%\end{array}$ & $\begin{array}{c}\text { Neutral } \\
\%\end{array}$ & $\begin{array}{c}\text { Contra } \\
\%\end{array}$ \\
\hline Rodrigo Medina & 35 & 53 & 65,6 & 34,4 & \\
Fernando Elizondo & 26 & 37 & 43,4 & 42,9 & 13,8 \\
Total & 63 & 73 & & & \\
\hline
\end{tabular}

\begin{tabular}{lccccc}
\hline Telediario matutino & $\begin{array}{c}\text { Núm. de } \\
\text { notas }\end{array}$ & $\begin{array}{c}\text { Tiempo } \\
(\mathbf{m} \text { in) }\end{array}$ & $\begin{array}{c}\text { Favor } \\
\%\end{array}$ & $\begin{array}{c}\text { Neutral } \\
\%\end{array}$ & $\begin{array}{c}\text { Contra } \\
\%\end{array}$ \\
\hline Rodrigo Medina & 12 & 42,6 & 68,6 & 23,2 & 8,3 \\
Fernando Elizondo & 14 & 50,0 & 66,0 & 20,5 & 13,5 \\
Total & 31 & 37 & & & \\
\hline
\end{tabular}

\begin{tabular}{lccccc}
\hline Telediario nocturno & $\begin{array}{c}\text { Núm. de } \\
\text { notas }\end{array}$ & $\begin{array}{c}\text { Tiempo } \\
(\text { min) }\end{array}$ & $\begin{array}{c}\text { Favor } \\
\%\end{array}$ & $\begin{array}{c}\text { Neutral } \\
\%\end{array}$ & $\begin{array}{c}\text { Contra } \\
\%\end{array}$ \\
\hline Rodrigo Medina & 5 & 17,1 & 80 & 20 & \\
Fernando Elizondo & 7 & 81,9 & 79 & 21 & \\
Total & 15 & 30 & & & \\
\hline
\end{tabular}


sobre ninguno de ellos. Es decir, se habló poco de ellos, pero en la mayoría de las ocasiones los locutores, comentaristas o reporteros se concretaron a dar cuenta de la información, absteniéndose de clasificar o manejar algún adjetivo que magnificara o descalificara a cualquiera de ellos. Esa situación no ocurrió, sin embargo, en el caso del candidato del PAN, sobre todo en la información que se dio a conocer a través del informativo matutino de Televisa Monterrey.

Los informativos matutino y nocturno de Televisa Monterrey y el matutino de TV Azteca fueron los que manejaron la mayor cantidad de noticias negativas hacia el candidato del PAN, al mismo tiempo que fueron aquellos que en términos reales ofrecieron la mayor parte de la información positiva del candidato del PRI. La propuesta de la sociología de la producción de mensajes refiere que cada una de las empresas periodísticas presenta y da a conocer la información de acuerdo con una serie de condicionantes que inciden en la forma como se estructura el mensaje. En este caso, el manejo de la información de parte de Televisa Monterrey hacia la candidatura del candidato del PAN fue negativa. Lo anterior es evidente si se repara que hacia el candidato del PRI no existe prácticamente ninguna información negativa, situación que difiere con la que se presenta hacia su principal contrincante.

\section{A manera de conclusiones}

La presentación que hicieron los noticieros de la televisión mexicana sobre la información relacionada con la contienda electoral para elegir al gobernador del Estado de Nuevo León, deja en evidencia que lo que menos interesaba a las empresas televisoras era ofrecer a su público el material suficiente para que este fuera capaz de tomar su propia decisión al momento de sufragar. De la misma manera como demuestran su interés por un determinado tema cuando a este le conceden mucho espacio y le tratan continuamente, también es posible deducir que no les interesa o se resisten a escribir sobre el tema. Las televisoras, en este caso, proporcionaron muy poca información a su público, y cuando lo hicieron lo colocaron en el sitio menos indicado, ya que para cuando eso sucedía en la mayoría de las veces se trataba de un horario inapropiado.

La poca atención que se dispensó a la contienda electoral para elegir gobernador de Nuevo León queda en evidencia si se repara que en algunos casos la cantidad de noticias que se transmitieron sobre el tema no llegó ni siquiera al promedio de una por día. Sin embargo, aun cuando la primera lectura deja entrever un desinterés por el tema, la realidad parece ser otra, ya que si bien cerraron el espacio a los candidatos en los informativos, abrieron sus puertas en los programas rela- 
cionados con el espectáculo y la pacotilla o crónica rosa. Lo anterior denota que la política editorial que asumieron las televisoras fue la de hacerse necesarias para los partidos políticos.

Nadie puede negar el papel que las televisoras han asumido en los procesos electorales tanto en México como en todos los países del mundo occidental. Tampoco es posible negar el poder que han construido con el paso del tiempo en este país, donde han pasado de ser un instrumento dependiente del sector político para convertirse en una institución cuyo poder se ubica a un nivel similar al de las instancias políticas. Los cambios generados en la legislación electoral han provocado su malestar y han demostrado que ellos no están dispuestos a obedecer los designios de los gobernantes de turno, y menos aún lo harán si la medida les reduce sus ganancias.

La evidente necesidad que tienen los políticos de la televisión hizo que los dos principales contendientes, principalmente el candidato del PRI, dejara los espacios informativos para concentrar su aparición en programas de espectáculos y en aquellos de tipo revista. En los programas se incluía entonces la figura del candidato, quien era "invitado" a participar en eventos situacionales; por ejemplo, el Día del Padre las conductoras de un programa de televisión resaltaron las cualidades paternales que tenía el candidato del PRI. Ese día, presentaron en las cáma- ras de la televisión a sus hijas (triates) y a su mujer, y se incluyó un reportaje en donde se aludía a las cualidades de dicho candidato.

En Televisa Monterrey se propusieron promocionar al candidato priista a costa de violar la reciente ley del Cofipe, y lo consiguieron. Sin duda que han encontrado rápidamente los recovecos por medio de los cuales estas empresas pueden evadir la reciente legislación. Específicamente en Nuevo León, las televisoras han dado muestras de que no obstante las reformas legales y los candados que se han puesto en funcionamiento, ellas siempre serán capaces de poner en práctica criterios extraperiodísticos desde los cuales se determina qué se informa, qué no se informa, pero también cómo se informa.

Entre las razones que argumentaban con mayor insistencia las televisoras en su afán por echar abajo la propuesta que habría de impedir que particulares pudieran comprar tiempo destinado a la propaganda, fue que al entrar esta en vigor se habría de violar el derecho que tienen los mexicanos a estar informados. Sin embargo, las evidencias indican que tradicionalmente estas empresas no han sido las más justas y mucho menos las más equilibradas al momento de informar a su público sobre las contiendas electorales. El desequilibrio informativo que se transmite a través de los noticieros de la televisión ha sido una 
constante, y en prácticamente todas las contiendas de las que se tenga referencia han sido evidentes este tipo de situaciones.

En la contienda del 2009 para elegir al gobernador del Estado de Nuevo León, la situación no varió en lo mínimo. La tendencia de los informativos fue la de enfocar la atención en solo dos de los cinco candidatos. Para las televisoras, sobre todo para Televisa Monterrey, el 93 por ciento del tiempo que destinaron al evento tuvo como protagonistas a los candidatos del PRI y del PAN. El tiempo restante se orientó al resto de los candidatos, pero también en ese mismo espacio se dedicaron a transmitir información relacionada con dos o más candidatos en donde se incluye principalmente a los del PRI y del PAN.

Más allá del poco espacio concedido al tema y de haber incluido en la mayor parte de las notas la información de dos de los cinco candidatos, a través de los noticieros regiomontanos se ofreció una pobre información, la cual sin duda tenía como propósito fundamental atraer la atención de la ciudadanía. Para ello recurrió a la elección de asuntos espectaculares y dejó al margen información más útil. Destacar los problemas que se generaron entre los seguidores de los candidatos, o las declaraciones de uno y otro, en nada beneficiaba al electorado. No se abordaron temas relacionados con la ecología y mucho menos se difundió la plataforma que habría de im- plementar cada uno de ellos. Tampoco sucedió con la estrategia para incrementar el empleo entre la población, la vialidad, etcétera.

En este caso se apostó más al rating y a la información superficial que a la reflexión y el análisis. Se repite la fórmula que tanto les ha resultado y es evidente que existe una fuerte relación en los intereses de las televisoras, principalmente de Televisa y el PRI. Este partido político sabe que la empresa más fuerte de televisión en México es importante para retomar el poder y ha encontrado a través de los infomerciales la oportunidad para que grupos de gobernadores destinen a sus arcas enormes sumas de dinero.

Lo más lamentable, en este caso, es que los partidos políticos en lugar de buscar la gobernabilidad y meter en cintura a la televisora, han permitido que una cantidad importante de legisladores del Partido Verde Ecologista de México hayan estado ligados a las empresas televisoras, como sucede con la diputada plurinominal por dicho partido, Ninfa Salinas Sada, hija de Ricardo Salinas Pliego. Por el lado de Televisa, también existe un grupo de diputados que de alguna forma han estado ligados a la televisora.

Seguramente que la elección federal del 2012 será una campaña en la que la televisión jugará un papel determinante, mientras tanto está consciente, dejándose querer, a sabiendas de que los grupos políticos más importantes del país le hacen las carava- 
nas y sabedores de que las televisoras no tienen memoria ni suelen agradecer los favores, ya que en el momento que otro contrincante les guiñe el ojo, seguro que aprovechará la oportunidad para lograr mejores condiciones $\mathrm{y}$, desde luego, dividendos políticos y económicos.

\section{Bibliografía}

Aceves González, Francisco de Jesús (enero-junio del 2004). "Monitoreo de medios y democratización en América Latina. La participación ciudadana en la vigilancia de la función informativa de los medios de comunicación de masas". Comunicación y Sociedad 1. Guadalajara: Universidad de Guadalajara.

Acosta Valverde, Miguel; Aguayo Quezada, Sergio y Javier Treviño Rangel (2009). Democracia: Medios de comunicación y elecciones en México. México D. F.: Fundar/Centro de Análisis e Investigación, A.C.

Aguayo QuezadA, Sergio y Miguel Acosta (1997). Urnas y pantallas. La batalla por la información. México D. F.: Océano.

Alva de la Selva, Alma Ros. (febrero-marzo del 2007). "La gran ganadora". Revista Mexicana de Comunicación 103. México D. F.

Arredondo Ramírez, Pablo (1991). "Opacidad en la ventana electrónica: El proceso electoral de
1988 en los noticieros televisivos", en Arredondo Ramírez, Pablo; Fregoso Peralta, Gilberto y Raúl Trejo Delarbre. Así se calló el sistema: Comunicación y elecciones en 1988. Guadalajara: Universidad de Guadalajara.

Arredondo Ramírez, Pablo; Fregoso Peralta, Gilberto y Raúl Trejo Delarbre (1991). Así se calló el sistema: Comunicación y elecciones en 1988. Guadalajara: Universidad de Guadalajara.

Encup (2009). “Encuesta Nacional sobre Cultura Política y Prácticas Ciudadanas". Segob. <http://www. encup.gob.mx/ncup/?page=cuartaencup-informe>.

Gans, H. (1979). Deciding what's news. Nueva York: Random House.

Herrera, Jorge (8 de octubre del 2006). "IFE: gasto de campañas en medios creció más de 100\%". El Universal. <http://0-http://0-proquest.umi. com.millenium.itesm.mx/pqdweb? $\mathrm{did}=1143178221 \& \mathrm{sid}=2 \& \mathrm{Fmt}=3 \& \mathrm{cli}$ entId $=23693 \&$ RQT $=309 \& V$ Name $=P$ QD>.

IgARTUA, Juan José y Ma. Luisa Humanes (2004). Teoría e investigación en comunicación social. Madrid: Síntesis.

Iyengar, S. y D. Kinder (1987). News that matter: Television and American opinion. Chicago: University of Chicago Press.

McCombs, Mawell (2006). Estableciendo la agenda. El impacto de la opinión 
pública y el conocimiento. Barcelona: Paidós Comunicación.

—. (1996). "Influencia de las noticias sobre nuestras imágenes del mundo", en Brayant, Jennyngs y Dolf Zillmann (comp.). Los efectos de los medios de comunicación. Investigación y teorías. Barcelona: Paidós.

Secanella, Petra María (1983). El periodismo político en México. Barcelona: Mitre.

Shoemaker, Pamela J. y Stephen D. Reese (1994). La mediatización del mensaje. Teorías de las influencias en el contenido de los medios de comunicación. México D. F.: Diana.

SigAL, León (1993). Reporteros y funcionarios. México D. F.: Gernika.

Treviño Rangel, Javier y Miguel Acosta Malverde (2007). Inequidad y miedo. Las elecciones del 2006 vistas por televisión. México D. F.: Propuesta Cívica/IFE.

Wimmer, R. y J. R. Dominick (1996). La investigación científica de la comunicación. Una introducción a sus métodos. Barcelona: Bosch Comunicación. 